\title{
Polyurethane Nanofiber Membranes for Waste Water Treatment by Membrane Distillation
}

\author{
T. Jiříček, ${ }^{1}$ M. Komárek, ${ }^{2}$ and T. Lederer ${ }^{2}$ \\ ${ }^{1}$ Membrain s.r.o., Pod Vinicí 87, 47127 Stráž pod Ralskem, Czech Republic \\ ${ }^{2}$ Technical University of Liberec, Studentská 1402/2, 46117 Liberec 1, Czech Republic \\ Correspondence should be addressed to T. Jiříček; tomas.jiricek@membrain.cz
}

Received 23 February 2017; Accepted 11 April 2017; Published 7 May 2017

Academic Editor: Piotr Nowicki

Copyright (C) 2017 T. Jiříček et al. This is an open access article distributed under the Creative Commons Attribution License, which permits unrestricted use, distribution, and reproduction in any medium, provided the original work is properly cited.

\begin{abstract}
Self-sustained electrospun polyurethane nanofiber membranes were manufactured and tested on a direct-contact membrane distillation unit in an effort to find the optimum membrane thickness to maximize flux rate and minimize heat losses across the membrane. Also salt retention and flux at high salinities up to $100 \mathrm{~g} \mathrm{~kg}^{-1}$ were evaluated. Even though the complex structure of nanofiber layers has extreme specific surface and porosity, membrane performance was surprisingly predictable; the highest flux was achieved with the thinnest membranes and the best energy efficiency was achieved with the thickest membranes. All membranes had salt retention above 99\%. Nanotechnology offers the potential to find modern solutions for desalination of waste waters, by introducing new materials with revolutionary properties, but new membranes must be developed according to the target application.
\end{abstract}

\section{Introduction}

As the demands for potable water are rising every year and more stringent environmental legislation is issued, there is a clear need for the development of new technologies and materials to meet these challenges. Even though many new approaches are examined every day in order to find a solution with lower energy consumption, higher effectivity, and the possibility of using alternative energy sources, most novelties are not as durable and reliable as existing technologies, such as reverse osmosis (RO). Future prospects of $\mathrm{RO}$, on the other hand, may seem quite complicated as the energy demands and brine production are both unsustainably high [1]. In this perspective, membrane distillation (MD) is theoretically a very attractive alternative: not pressure but temperature driven up to saturated concentrates, with high salt rejection and possibility of being powered by solar or geothermal energy, or low-graded waste heat [2]. What has always held MD from becoming a mainstream technology were suitable membranes, or more precisely the lack of them, which would provide fluxes comparable with traditional RO. Hence, the interest to develop new membranes specifically for MD has been quite intense in recent years [1].
When developing new membranes for $\mathrm{MD}$, the maximisation of membrane permeability and hydrophobicity in terms of bubble point pressure and contact angle are obviously desirable, as are low fouling and chemical and mechanical stability [3]. Even though membrane thickness is a key parameter, its role is not quite straightforward, but at least it is generally acknowledged that thin membranes with large pores provide high fluxes and that thick membranes with small pores minimize heat losses via conduction [4]. Even though approximate ranges were suggested, including a simulation using the Dusty Gas Model [3], there is still no clear understanding what the optimum membrane thickness is. Although nanotechnology has a significant potential role in membrane based desalination [1], information about optimum structural parameters for nonwoven membranes is even scarcer and therefore deeper study is most relevant. Nanofibers are typically created by an electrostatic field from a polymer solution by electrospinning [5] and both high porosity and hydrophobicity are declared $[6,7]$.

Electrospun nanofiber membranes have significantly better transmembrane fluxes than currently used hydrophobic microfiltration membranes $[8,9]$. Polyfluorinated polymers that have been tested recently [10-12] displayed excellent 
hydrophobicity, but they also prove electrospinning difficult, thus restraining the possibility for a deeper study involving many layers of varying properties. Polyurethane (PUR), on the other hand, allows for adjustment of membrane thickness both by varying substrate velocity and by placing several layers onto each other; moreover, they do not require any kind of mechanical support, thus avoiding a performance deteriorating step of thermal-pressure lamination [9].

The novelty of this work consists of electrospinning and testing nonlaminated, self-sustained PUR membranes for the application of MD in waste water treatment. Their performance was evaluated in terms of transmembrane flux, energy efficiency, and salt retention, including the test at various recirculation velocities and several different salt concentrations of the feed solution.

\section{Materials and Methods}

The flat sheet nanofiber PUR membranes were prepared by continuous needleless electrospinning process, using the NanoSpider ${ }^{\mathrm{TM}}$ spinner (Elmarco). PUR resin (Larithane Al286, Novotex Italiana S.p.A., molecular weight $2000 \mathrm{~g} \mathrm{~mol}^{-1}$, technical grade quality, supplied as 30\% w./w. solution in DMF) and N,N-dimethylformamide (SigmaAldrich) were both used as received. The polymer solution was prepared by dissolving the PUR polymer in DMF. The polymer concentration was set to $18 \% \mathrm{w}$./w. The solution was stirred for 2 hours at $21^{\circ} \mathrm{C}$ on a magnetic stirrer in a sealed beaker to prevent the solvent evaporation.

NanoSpider ${ }^{\mathrm{TM}}$ is equipped with a $0.2 \mathrm{~mm}$ wire emitting electrode and a static wire collecting electrode. The polymer solution is applied on the emitting electrode by a moving applicator. Both electrodes are attached to the high voltage power supply. The voltage between electrodes was set to $70 \mathrm{kV}$ and the distance between the electrodes was kept constant at $175 \mathrm{~mm}$. Relative humidity in the electrospinning chamber was kept below $20 \%$ at $24^{\circ} \mathrm{C}$ to minimize the formation of defects. The nanofibers were collected on a nonadhesive paper substrate passing between emitting and collecting electrode. Production speed varied according to the desired nanofiber membrane sheet thickness.

Four different individual membranes were manufactured with a varying surface density in grams per square meter (GSM) to be $6,10,25$, and $40 \mathrm{~g} \mathrm{~m}^{-2}$, designated as PUR06, PUR10, PUR25, and PUR40. The lower weight membranes $\left(6\right.$ and $10 \mathrm{~g} \mathrm{~m}^{-2}$ ) were prepared in one step by variation of the substrate speed. The two thicker membranes were prepared by multiple passing of the substrate material through the spinning chamber, PUR 25 by 3 passes and PUR 40 by 5 passes. The prepared nanofiber membranes were designed to be self-supporting; thus lamination process was not necessary. Mechanical properties of the PUR membranes were sufficient for handling of the membranes and application in MD.

The membranes were tested on a laboratory scale directcontact (DCMD) unit with a $0.02 \mathrm{~m}^{2}$ flat sheet module. Countercurrent recirculation was powered by a peristaltic pump with two rotors. Two feed temperatures of 50 and $60^{\circ} \mathrm{C}$ were tested, in order to assess the potential thermal deterioration of not-so-temperature-resistant PUR membranes.
Temperatures were measured via four thermocouples in the module inlet and outlet pipes. Two hot baths, Julabo F12 and Lauda RE 420, were used to set the driving force according to the logarithmic mean temperature difference (LMTD) and were kept at $10^{\circ} \mathrm{C}$ in all the experiments.

(i) Transmembrane flux was evaluated with demineralized water in both feed and distillate circuits, with cross-flow velocity ranging between 60 and $90 \mathrm{~mm} \mathrm{~s}^{-1}$, and was calculated as a difference in the distillate mass on a A\&D EK-12Ki scale.

(ii) Membrane retention was tested with various sodium chloride concentrations in the feed solution, up to approximately $100 \mathrm{~g} \mathrm{~kg}^{-1}$, and it was calculated as

$$
R=1-\frac{c_{d}}{c_{f}},
$$

where $c_{f}$ is the feed concentration and $c_{d}$ is the distillate concentration. The electrical conductivity was measured by WTW TetraCon probes connected to WTW Mutli9430 and WTW Multi350i.

(iii) Flux decline with increasing feed concentration was measured at approximately $85 \mathrm{~mm} \mathrm{~s}^{-1}$.

(iv) Energy efficiency was measured at four circulation velocities $\left(60,70,80\right.$, and $\left.90 \mathrm{~mm} \mathrm{~s}^{-1}\right)$ and calculated as

$$
E=\frac{N \cdot d H \cdot A}{m \cdot C_{p} \cdot d T},
$$

where $N$ is flux, $d H$ is the enthalpy of condensation, $A$ is the membrane area, $m$ is the mass flow rate along the membrane, $C_{p}$ is the heat capacity, and $d T$ is the temperature difference at the inlet and outlet of the module.

POROMETER 3G (Quantachrome) was used to measure the bubble point pressure and pore sizes by a wet-dry flow method. Optical Tensiometer THETA QC (Attension) was used to measure the contact angle with demineralized water, giving an average of the right and left angle.

Tescan Vega3SB (CZ) was used to study the membrane structure and thickness. This high vacuum scanning electron microscope measures the $\mathrm{Au} / \mathrm{Pt}$ coated samples at an acceleration voltage of $30.0 \mathrm{kV}$. The cross section thicknesses of the membranes were obtained by breaking the frozen membranes in liquid nitrogen. To obtain the fiber dimensions and membrane thickness, image analysis was done in Tescan software.

\section{Results and Discussion}

3.1. Membrane Characterisation. The main goal of this work is to evaluate how structural parameters of nanofiber membranes (Table 1) affect MD performance. Here, the membrane thickness clearly correlates with the surface density. The maximum pore size of all samples stays below $1 \mu \mathrm{m}$ and 
TABLE 1: Membrane structural properties.

\begin{tabular}{lcccccc}
\hline Membrane code & Thickness $(\mu \mathrm{m})$ & $\begin{array}{c}\text { GSM } \\
\left(\mathrm{g} \mathrm{m}^{-2}\right)\end{array}$ & Contact angle $\left(^{\circ}\right)$ & $\begin{array}{c}\text { Max. pore } \\
\text { size }(\mu \mathrm{m})\end{array}$ & $\begin{array}{c}\text { Min. pore } \\
\text { size }(\mu \mathrm{m})\end{array}$ & $\begin{array}{c}\text { Bubble point pressure } \\
(\mathrm{bar})\end{array}$ \\
\hline PUR06 & 10 & 6.0 & 97.8 & 0.8638 & 0.3194 & 0.7425 \\
PUR10 & 16 & 10.0 & 119.0 & 0.6424 & 0.3539 & 0.9965 \\
PUR25 & 74 & 25.6 & 127.2 & 0.4986 & 0.4469 & 1.2834 \\
PUR40 & 148 & 40.1 & 132.0 & 0.4987 & 0.4438 & 1.2839 \\
\hline
\end{tabular}
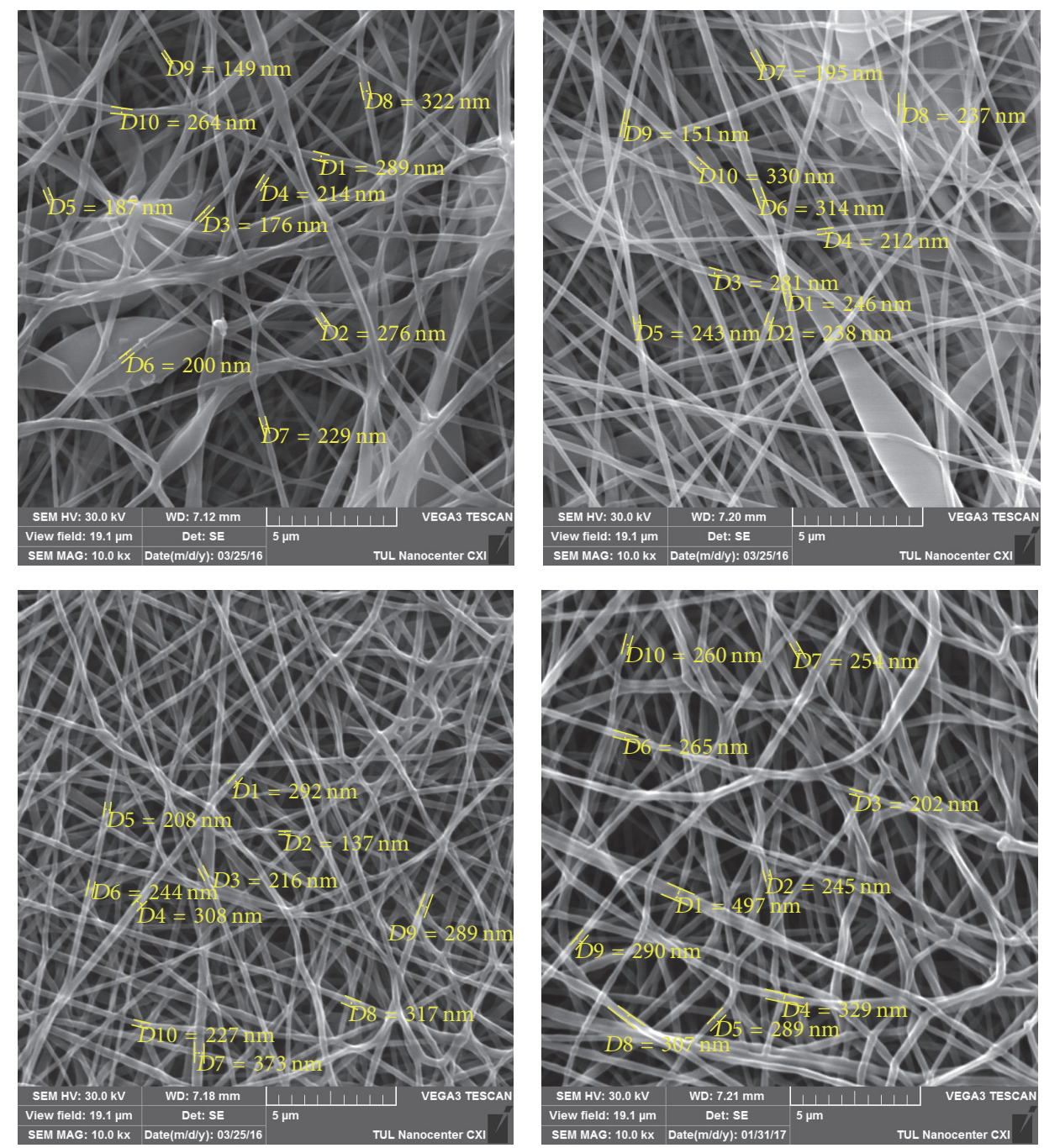

FIGURE 1: Perpendicular SEM micrographs of membrane structure (10.000x): PUR40, PUR25, PUR10, and PUR06.

the difference between maximum and minimum pore size decreases with membrane thickness. Nonwoven layers do not have pores as such; rather they contain irregular void interconnected spaces, so the porometer which assumes unitary tubular pores judges thicker membranes as if they had smaller pores. Also, the bubble point pressure increases with membrane thickness and the value above 1 bar is very good, considering that no hydrophobic posttreatment, such as $\mathrm{CF}_{4}$ plasma, was used on the finished layers. Another measure of membrane hydrophobicity is the contact angle which is approaching very high values for the thickest PUR40 membrane.

Nanofiber membranes have a similar look and similar fiber diameter; however mainly the thicker samples display certain irregularity in the form of polymer drops and solvent fusing (Figure 1). This aspect can be attributed to the changes of the electrostatic field during the electrospinning of the thick layers, because at such thicknesses the electrical shielding of the nanofiber layer becomes inconsiderable. The fiber diameter distribution does not show statistically significant 

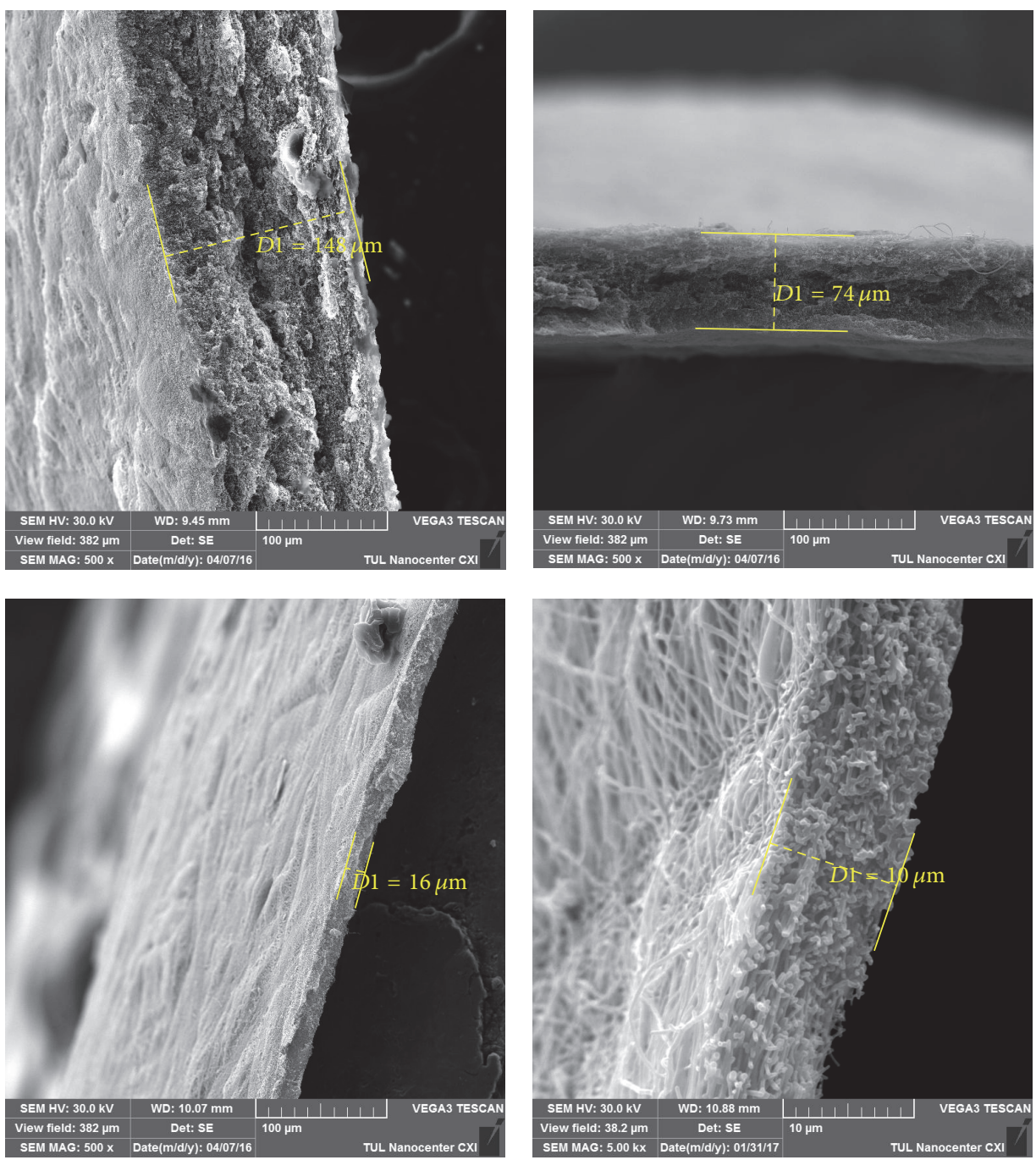

Figure 2: Cross section of membranes: PUR40 (500x), PUR25 (500x), PUR10 (500x), and PUR06 (5.000x).

differences among the samples. The average diameters were measured to be $260 \mathrm{~nm}$ having the standard deviation of $62 \mathrm{~nm}$. The average was calculated from the 10 measurements per sample.

The cross-sectional micrographs (Figure 2) contain the measurement of membrane thickness, which is in relative accordance with the membrane surface density. The increase of the thickness should be linear with the increase of surface density, because only one space dimension actually changes. Deviations from this behaviour may be attributed to the relatively higher presence of bead defects in the thinner layers. The ratio of GSM and membrane thickness (i.e., the volumetric mass density) of single-pass PUR06 and PUR10 is about twice that of PUR25 and PUR40, fabricated in multiple passes. Therefore it is suggested that the way of membrane fabrication affects its density which may substantially influence its performance.

3.2. Membrane Performance. The effect of cross-flow velocity on transmembrane flux is positive (Figure 3) and correlates with previously published results [9]. All tested samples responded positively on recirculation velocity increase at both $50^{\circ} \mathrm{C}$ and $60^{\circ} \mathrm{C}$, maintaining the identical driving force of LMTD $=10^{\circ} \mathrm{C}$. Overall, the fluxes of thicker membranes PUR10, PUR25, and PUR40 are higher by 30 to $40 \%$ with warmer feed. According to a calculation from Antoine's equation, the difference in partial vapour pressure is about $60 \%, 12.3 \mathrm{kPa}$ and $19.9 \mathrm{kPa}$ for $50^{\circ} \mathrm{C}$ and $60^{\circ} \mathrm{C}$, respectively. Interestingly, the thinnest membrane PUR06 had nearly identical fluxes at either temperature. Therefore, some kind of driving force limitation occurs at very low membrane thickness, supposedly a combination of the heat losses by conduction and pore wetting.

As the membrane itself is a net resistance to mass transport, transmembrane flux increases with membrane thickness and the only limit seems to be the physical coherence of the nanofiber layer. The thinnest PUR06 was indeed very difficult to manipulate and the measurement had to be repeated many times due to tiny membrane ruptures that appeared during the tests, most probably caused by an 

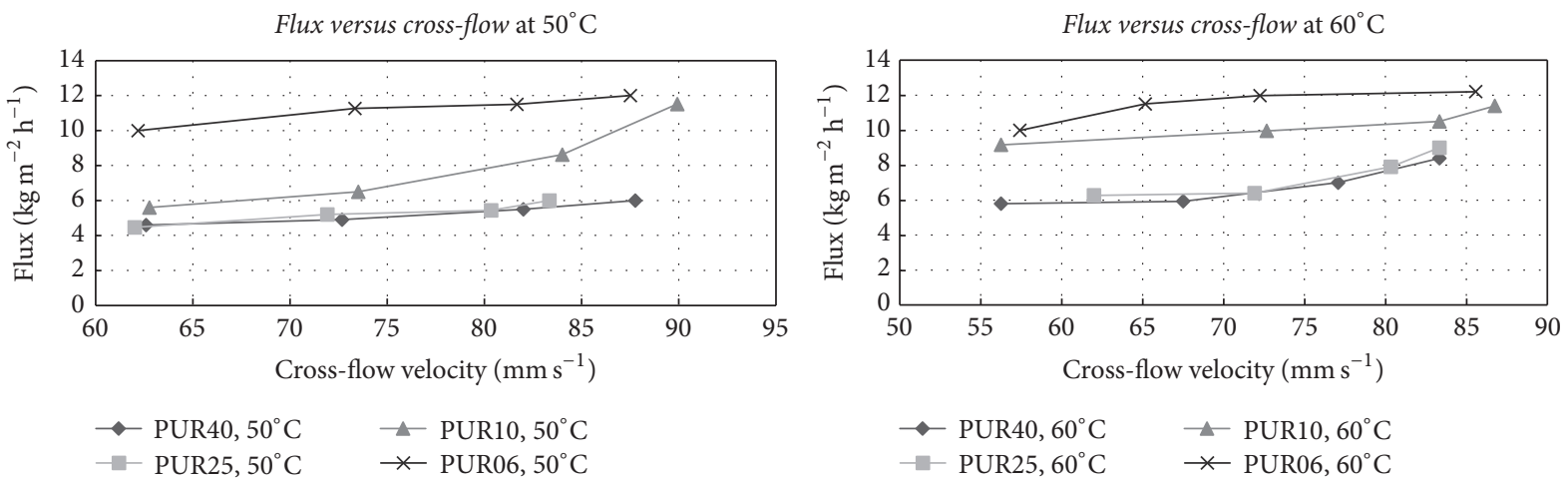

FIGURE 3: The effect of tangential velocity on transmembrane flux at $50^{\circ} \mathrm{C}$ and $60^{\circ} \mathrm{C}$.

Thermal efficiency at $50^{\circ} \mathrm{C}$

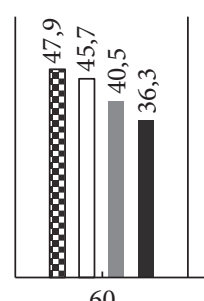

60

슨

\section{(1)}

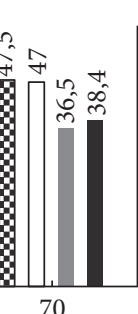

PUR10
PUR06

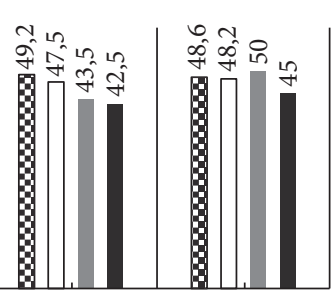

80
90

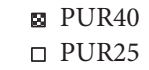

60
Thermal efficiency at $60^{\circ} \mathrm{C}$

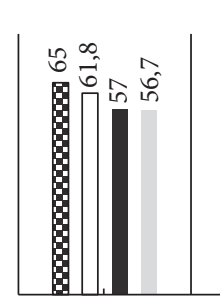

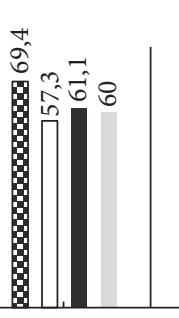

70

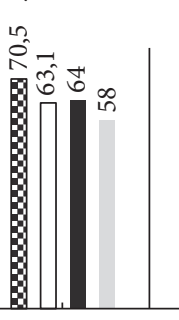

80

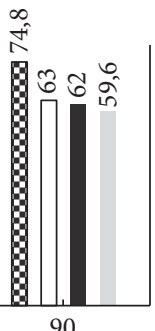

- PUR10

PUR06

FIgURE 4: The effect of membrane thickness on process efficiency.

indelicate clamping onto the membrane spacer. Over time, no significant performance drop has been observed for either feed temperature, suggesting that PUR membranes have sufficient thermal stability, a key aspect to MD membranes.

MD efficiency is the ratio of the efficient vapour condensation heat over the total heat transported across the membrane and theoretically should increase with higher cross-flow velocities, given that the driving force of LMTD accounts for all four inlet and outlet temperatures. Thermal efficiency increases with membrane thickness and cross-flow velocity, as well as with feed temperature for any tested membrane (Figure 4).

Still, the differences between various nanofiber membranes are in the range of several percent; therefore, to achieve the same flux in practical application, it will be the process operating expenses governing the decision whether thinner membranes are more desirable than higher feed temperatures or extreme recirculation velocity.

The primary objective of all MD membranes is to retain maximum dissolved solids, and, unlike pressure driven processes, only small flux decline is to be expected at high water recoveries. The differences in distillate purity were negligible, as $99.9 \%$ of salts were retained in the feed (Figure 5).

On the other hand, transmembrane flux is affected by the feed concentration. This is most evident using the thinnest membrane, which at highest salinities did not exhibit any flux at all (Figure 5). Even though the difference in membrane thickness from the first thicker membrane PUR10 is mere $6 \mu \mathrm{m}$, it actually signifies more than 50\% of the PUR06 thickness.

The flux of the two thickest membranes, PUR40 and PUR25, seems to be least affected by the feed salinity, as even in $10 \%$ brine the flux drops only to $71 \%$ and $64 \%$ of the initial value, respectively, which are results not even imaginable with RO. There is an obvious pattern between thinner membranes with more layers and the thinner single-pass PUR10 and PUR06, as their flux drops by 70 and $98 \%$, respectively.

Open structure of nanofiber layers, especially without any hydrophobic treatment, is prone to small water molecules penetrating inside the membrane, causing pore wetting and flux decline [13]. This is best evidenced by the thinner samples, which have larger pore sizes and lower bubble point pressures (Table 1), resulting in unfavourable $\mathrm{MD}$ performance.

For removal of salts from waste water, thicker membranes seem to be a better solution. Thanks to their robust construction, more fluent operation with better energy efficiency can be expected. Probably the best sample is indeed the thickest PUR40, which has the same fluxes as PUR25, but with better thermal efficiency. Unless extreme fluxes are required, the 

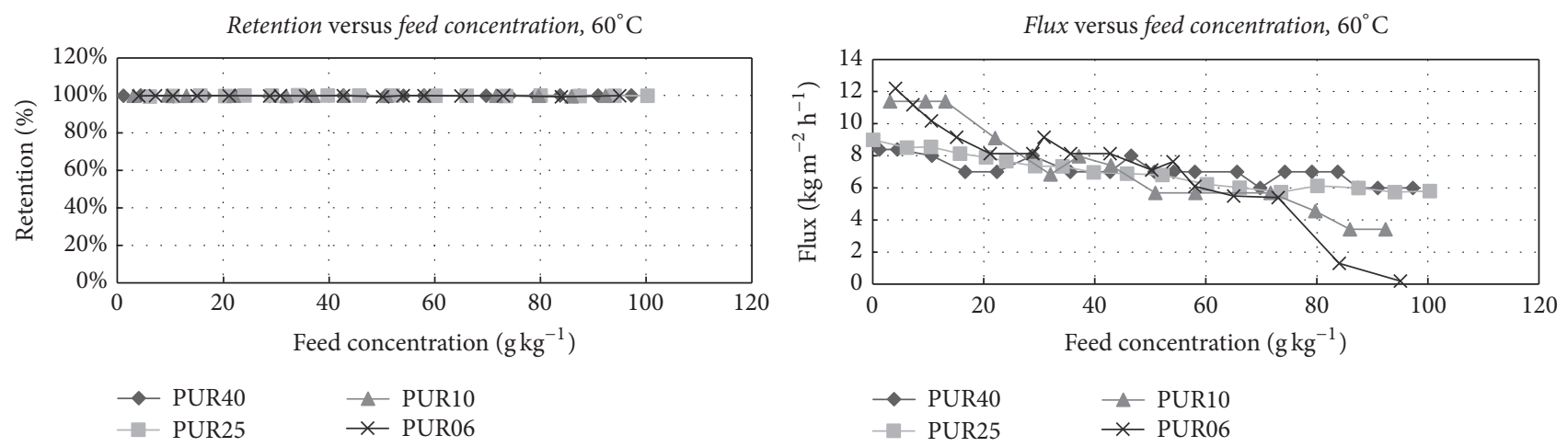

FIgURE 5: Retention and flux profile at different salinities at $60^{\circ} \mathrm{C}$ of feed temperature.

thinnest membrane PUR06 with a thickness of $10 \mu \mathrm{m}$ is to be avoided, mainly because of the severe flux fall-off at higher feed concentration.

\section{Conclusion}

Four PUR membranes with varying thickness have been fabricated and tested to find the optimum structural parameters and operational conditions for the best MD performance in waste water treatment.

The highest flux was achieved with the thinner membranes and the best energy efficiency was achieved with the thicker membranes. Also it is suggested to opt for higher mechanical strength of the membranes in order to maintain the transport properties and the possibility of treating very saturated solutions. From the heat and mass transfer point of view, the membranes are best operated at high recirculation velocity and with higher feed temperatures, although both of these operational conditions should be adjusted according to the particular feed and economical aspects.

The highly porous and interconnected structure of nanofiber membranes helped to overcome the conflicting and complex structural requirements of MD, potentially introducing a breakthrough technology for modern waste water treatment. However, there are several significant challenges to be solved before MD becomes a mainstream technology:

(i) The best overall performance is a compromise between flux and energy efficiency, and the best balance was achieved with the thicker membranes.

(ii) The ability to produce sufficiently large membrane surfaces may limit the overall unit capacity.

(iii) Even though the final price would strongly depend on the polymer type and thickness, generally it is in the range of 30 to $100 \$ \mathrm{~m}^{-2}$ which is several times more than that of RO.

\section{Abbreviations and Symbols}

A: Membrane area $\left(\mathrm{m}^{2}\right)$

$C_{p}$ : Heat capacity at constant pressure $\left(\mathrm{J} \mathrm{kg}^{-1} \mathrm{~K}^{-1}\right)$

$C_{f}$ : Feed concentration $\left(\mathrm{g} \mathrm{kg}^{-1}\right)$
$C_{d}: \quad$ Distillate concentration $\left(\mathrm{g} \mathrm{kg}^{-1}\right)$

DCMD: Direct-contact membrane distillation

$d H: \quad$ Enthalpy of condensation $\left(\mathrm{J} \mathrm{kg}^{-1}\right)$

$d T: \quad$ Temperature difference $(\mathrm{K})$

DMF: Dimethylformamide

E: $\quad$ Energy efficiency (\%)

GSM: Surface density $\left(\mathrm{g} \mathrm{m}^{-2}\right)$

LMTD: Logarithmic mean temperature difference

$\left({ }^{\circ} \mathrm{C}\right)$

$m: \quad$ Mass flow rate $\left(\mathrm{kg} \mathrm{s}^{-1}\right)$

MD: Membrane distillation

N: $\quad$ Transmembrane flux $\left(\mathrm{kg} \mathrm{m}^{-2} \mathrm{~h}^{-1}\right)$

PUR: Polyurethane

$R: \quad$ Retention (\%)

RO: Reverse osmosis

SEM: Scanning electron microscopy.

\section{Conflicts of Interest}

The authors declare that there are no conflicts of interest regarding the publication of this paper.

\section{Acknowledgments}

The presented results were achieved in the framework of the project LO1418 "Progressive Development of Membrane Innovation Centre," supported by the program NPU I Ministry of Education, Youth and Sports of the Czech Republic, using the infrastructure of the Membrane Innovation Centre. The research was also supported by the Ministry of Education, Youth and Sports in the framework of the targeted support of the "National Programme for Sustainability I" LO 1201 and the OPR\&DI project "Centre for Nanomaterials, Advanced Technologies and Innovation," CZ.1.05/2.1.00/01.0005.

\section{References}

[1] E. Drioli et al., "Membrane distillation: recent developments and perspectives," Desalination, vol. 356, pp. 56-84, 2015.

[2] A. Alkhudhiri et al., "Membrane distillation: a comprehensive review, Desalination, vol. 287, pp. 2-18, 2012. 
[3] L. Eykens et al., "How to optimize the membrane properties for membrane distillation: a review," Industrial \& Engineering Chemistry Research, vol. 55.35, pp. 9333-9343, 2016.

[4] Sulaiman Al-Obaidani et al., "Potential of membrane distillation in seawater desalination: thermal efficiency, sensitivity study and cost estimation," Journal of Membrane Science, vol. 323, pp. 85-98, 2008.

[5] F. Yener and O. Jirsak, "Comparison between the needle and roller electrospinning of polyvinylbutyral," Journal of Nanomaterials, vol. 13, 2012.

[6] A. Razmjou et al., "Superhydrophobic modification of $\mathrm{TiO} 2$ nanocomposite PVDF membranes for applications in membrane distillation," Journal of Membrane Science, vol. 415, pp. 850-863, 2012.

[7] C. Yang et al., "CF4 plasma-modified superhydrophobic PVDF membranes for direct contact membrane distillation," Journal of Membrane Science, vol. 456, pp. 155-161, 2014.

[8] L. Eykens et al., "Characterization and performance evaluation of commercially available hydrophobic membranes for direct contact membrane distillation," Desalination, vol. 392, pp. 6373, 2016.

[9] T. Jiříček et al., "Flux enhancement in membrane distillation using nanofiber membranes," Journal of Nanomaterials, 2016.

[10] Y. C. Woo et al., "Electrospun dual-layer nonwoven membrane for desalination by air gap membrane distillation," Desalination, 2015.

[11] M. Ma et al., "Electrospun poly (styrene-block-dimethylsilox ane) block copolymer fibers exhibiting superhydrophobicity," Langmuir, pp. 5549-5554, 2005.

[12] J. Zhang and Stephen Gray, "Effect of applied pressure on performance of PTFE membrane in DCMD," Journal of Membrane Science, pp. 514-525, 2011.

[13] Y. Liao et al., "Fabrication of polyvinylidene fluoride (PVDF) nanofiber membranes by electro-spinning for direct contact membrane distillation," Journal of Membrane Science, vol. 425, pp. 30-39, 2013. 

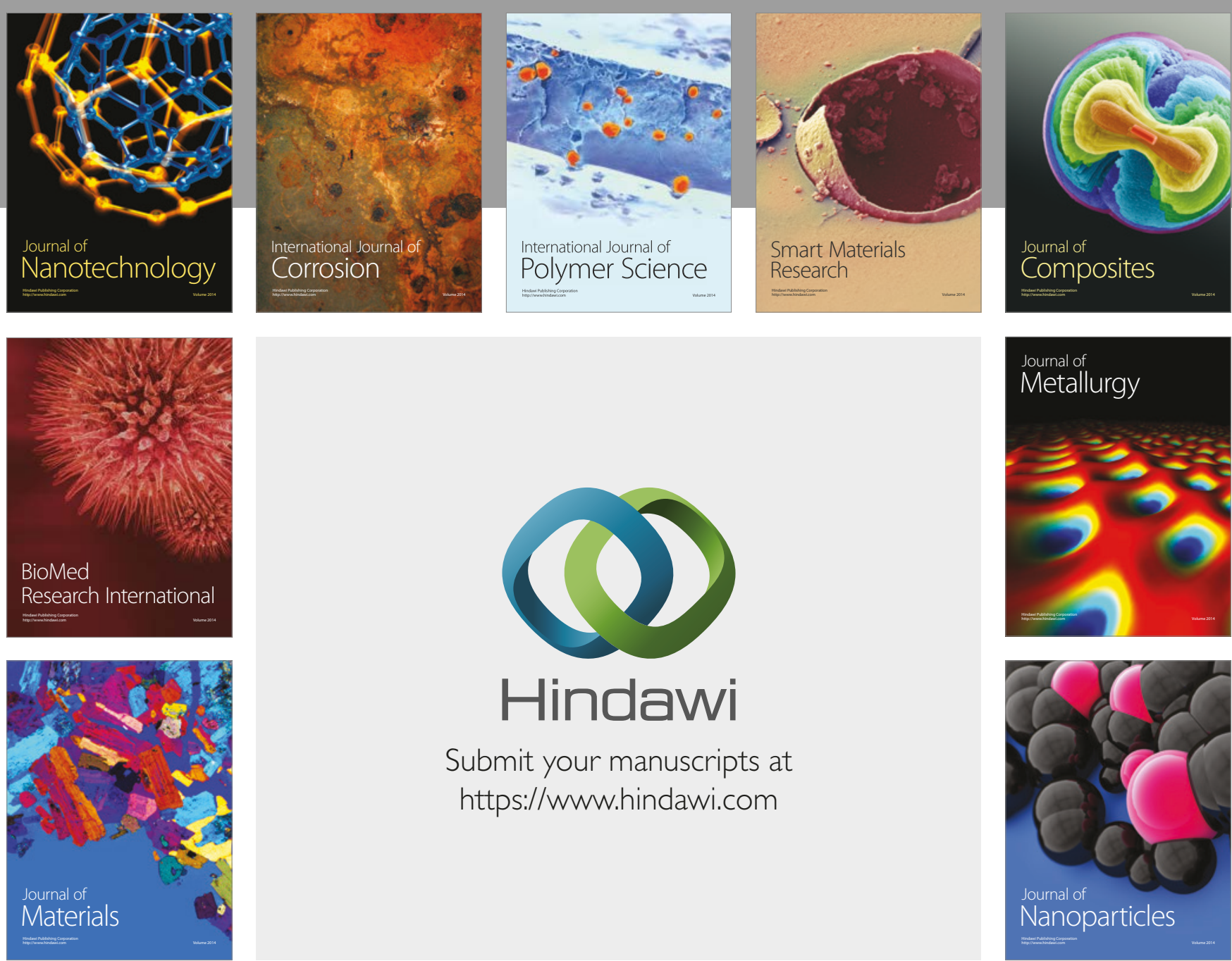

\section{Hindawi}

Submit your manuscripts at

https://www.hindawi.com
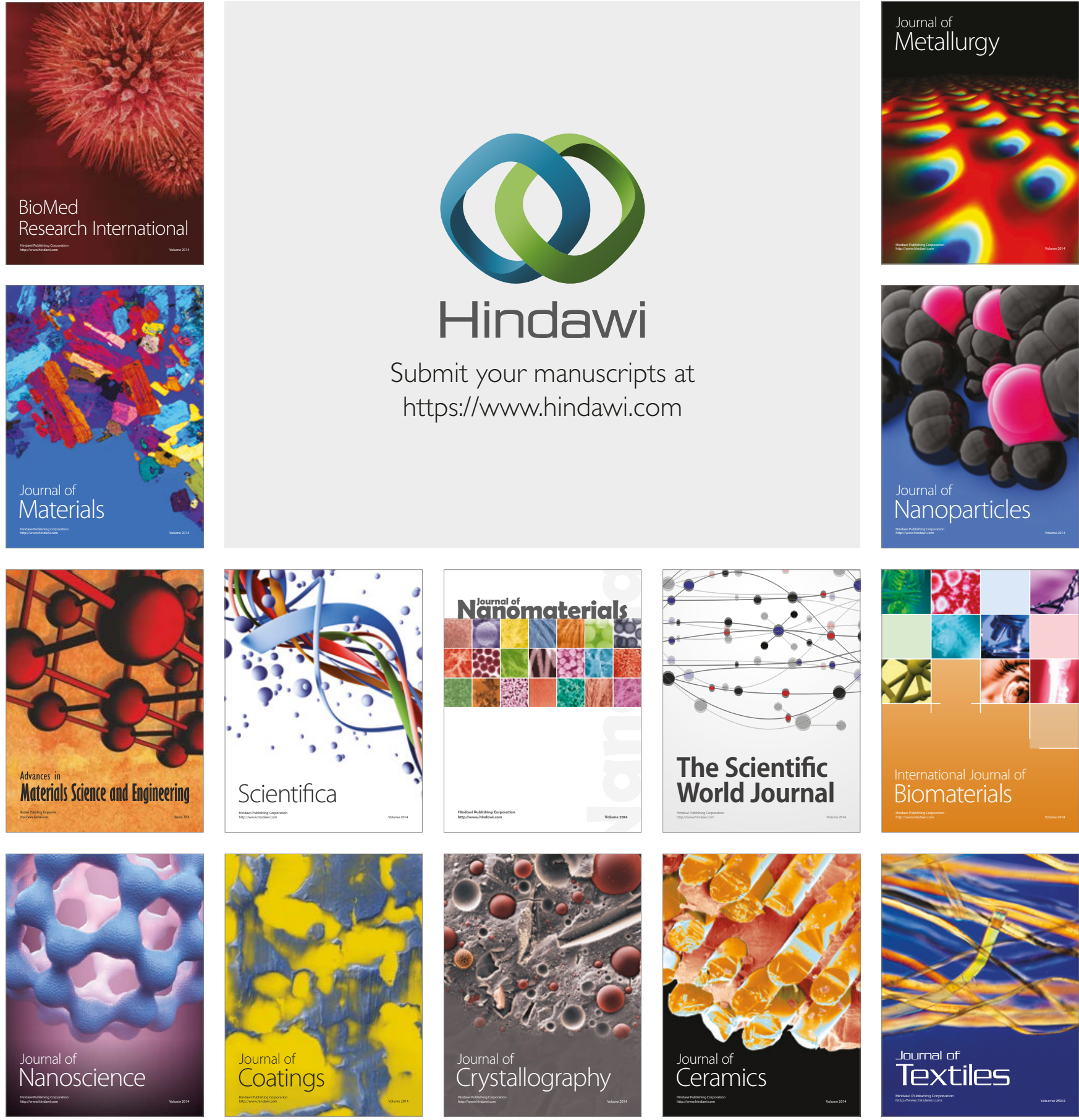

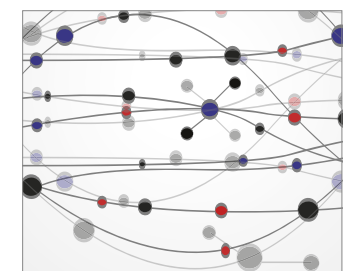

The Scientific World Journal
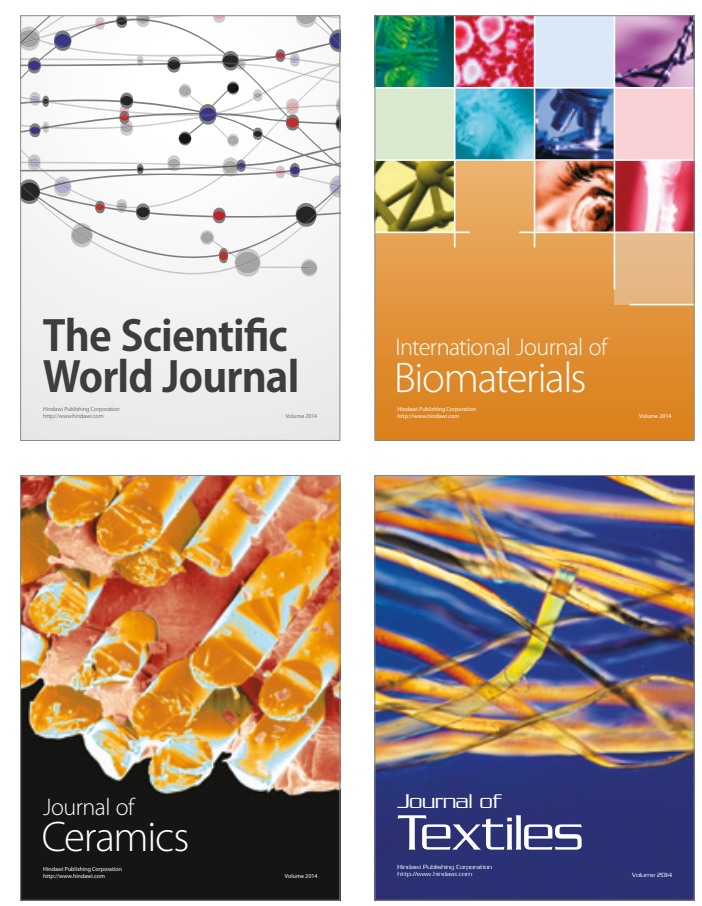